ORIGINAL ARTICLE

\title{
Knowledge, Experiences and Training Needs of Health Professionals about Disaster Preparedness and Response in Southwest Ethiopia: a cross sectional study
}

\author{
Negalign Berhanu $^{1}$, Hailay Abrha ${ }^{2}$, Yohannes Ejigu ${ }^{1}$, Kifle Woldemichael ${ }^{2}$
}

ABSTRACT

BACKGROUND: Over the past decade, the magnitude and intensity of disasters have been vividly rising globally due to the forces of nature or man. This study aimed at assessing the perceived knowledge, experiences and training needs of health professionals regarding disasters, their prevention and management in Jimma Zone, Southwest Ethiopia.

METHODS: An institution based cross-sectional survey was conducted on 377 health professionals taken from 9 randomly selected districts out of 18. All health professionals working at health offices, hospitals and health centers were included. Data were collected using a structured questionnaire which was developed by the investigators after reviewing the relevant literature in the field. Data were coded and entered into SPSS 20 software for cleaning and analysis. Descriptive and logistic regression analyses were done.

RESULTS: The majority (85.1\%) of the participants were able to define the concept of disaster from various perspectives; $9.7 \%$ did not know about it at all and $5.2 \%$ could describe the concept partially or misconceived it. The majority (84.3\%) agreed that disaster has direct public health consequences on humans. The main public health consequence of disaster the participants mentioned was environmental pollution (65.8\%). Malaria, measles and diarrhoeal diseases accounted for $35.5 \%$, 33.1\% and $10.5 \%$ of the epidemics, respectively. Only $20.6 \%$ of the respondents were trained on disaster related topics in the last two years.

The majority felt that they had poor knowledge on early warning indicators of drought (48.0\%) and flood (48.0\%). Simialry, 50.8\%, 47.7\%, 51.1\% and 42.6\% of the participants had poor knowledge on preparedness to drought, preparedness to flood, response to drought, response to flood. On composite scale, they generally perceived to have adequate (29.4\%), moderate (32.4\%) and poor (38.2\%) knowledge about early warning information bout, preparedness for and response to common disasters. A vast majority (92.8\%) reported that they need training on disaster preparedness, management and response.

CONCLUSION: A considerable number of professionals had limited understanding about the concept of disaster and response to certain specific disasters. They also had limited opportunities for training,despite their felt needs. Therefore, training should be provided focusing on the specific gaps identified.

KEYWORDS: training needs, disaster, knowledge, experience, health professionals, Jimma, Ethiopia

\section{DOI: http://dx.doi.org/10.4314/ejhs.v26i5.3}

\section{INTRODUCTION}

Disaster is a serious disruption of the functioning of society, causing widespread human, material or environmental losses, which exceed the ability of the affected communities to cope using their own resources (1). Globally, over the past decade, the magnitude and intensity of disasters have been vividly rising due to the forces of nature or man (2). In Ethiopia, droughts and floods have been the most common natural hazards (3).

Disaster has been causing serious physical, mental, social, environmental, and economic

\footnotetext{
${ }^{1}$ Department of Health Economics, Policy and Management, Jimma University, Jimma, Ethiopia

${ }^{2}$ Department of Epidemiology, Jimma University, Jimma, Ethiopia

Corresponding Author: Negalign Berhanu, Email: negenu@gmail.com
} 
crises (4-6). To prevent the loss of life and the impact of disaster, there is a need for community residents, health professionals and others to have readiness in emergency preparedness or disaster response. The relief and assistance mainly carriedout by medical rescue teams amongst health professionals are the key (7). Disaster medicine training, an integral part of efficient disaster preparedness, is vital for health professionals to develop comprehensive skills for preventing and alleviating disaster complications. Much has been said by the developed countries (810). For example, data from USA suggested that health professionals do not currently feel competent or knowledgeable in disaster medicine although they would like to be (8). This study also stated that many clinicians reported feeling illequipped to deal with a case of bioterrorism concerns though their levels of knowledge of bioterrorism were similar regardless of clinical specialty, educational degree, or number of years of practice.

Conversely, data from developing countries is very scanty. A cross-sectional survey in Shanghai, China, reported that merely $3.4 \%$ of the participants rated themselves as good regarding disaster medicine knowledge while $62.9 \%$ and $31.4 \%$ of the participants rated it as moderate and little (2), respectively. Regarding the training needs, more than $50 \%$ of health professionals need training and out of these, basic principles of disaster rescue $(74.0 \%)$, treatment principles and first-aid skills $(69.8 \%)$ and psychological relief (64.4\%) (2) were the major contents. Another cross-sectional study in Johannesburg Hospital of South Africa also showed that $92 \%$ of the study participants knew what a disaster is but only $62.5 \%$ knew what disaster preparedness is (11). According to this study, they needed to know about disaster, disaster plans and disaster response, and all felt that training is necessary for all health management on top of the necessity and regular update of disaster plans and its response. Educational level, age, professional title, number of years of practice, clinical specialty and degree of the hazard were among the factors associated with the level of knowledge and attitude score among health professionals $(2,8,11)$. To the best of our knowledge, no study has been found on this issue in Ethiopia.
With natural and or manmade disasters occurring more frequently across our nation and the fact that public health professionals are also facing new challenges, it is clear that they require competencies in public health preparedness and response. The current medical education and assessment criterion has been largely clinically oriented as disaster medicine has been long neglected though some limited efforts have been made to implement it in Ethiopia. Addressing knowledge, experiences and training needs of health professionals about disaster preparedness and response will help know the key components of first responders to disaster, i.e., health professionals should be sufficiently trained to perform timely and effective medical rescue. Therefore, the aim of the study was to assess the perceived knowledge, experiences and training needs of health professionals regarding disasters, their prevention and management in Jimma Zone, Southwest Ethiopia.

\section{METHODS}

Jimma Zone is located $357 \mathrm{Kms}$ Southwest of Addis Ababa, the Capital City of Ethiopia. It is is bordered to the south by the Southern Nations, Nationalities and Peoples Region, to the northwest by Illubabor Zone, to the north by East Welega Zone, and on the northeast by West Shewa Zone. The zone is divided in to 18 districts and one town administration with a total of 545 Kebeles (the smallest administrative unit) of which 515 are rural. The total projected population of the zone is $2,486,155$ of which $89.69 \%$ are rural inhabitants. Regarding health institutions, the zone has 3 governmental hospitals, 54 health centers and 117 health posts. There are a total of 741 health care providers in the zone. Data were collected from March 15 to 30, 2014.

An institution based cross-sectional survey was conducted in 9 randomly selected districts out of the total of 18. All health professionals working in the selected districts were the source population, and those sampled professionals having a minimum educational level of diploma were the study population. The sample size was determined by using the single population proportion formula assuming the proportion of health professionals who needed training on disaster preparedness and response as 50\% (2), and $5 \%$ margin of error. Compensating for the 
non-response rate of $5 \%$, the final sample size was 404. The list of all health professionals working at health office, hospital and health center levels in the selected districts was used as a sampling frame. At each level, participants were randomly selected by lottery method. If a sampled participant was found to be ineligible during the visit to an institution, the next participant was sampled in the same way. Health professionals from private health institutions were not included in the study to avoid double counting as most of them might work both in public and private institutions. Participants, who were unable to give information due to various reasons such as illness or leave were also excluded.

A structured questionnaire was developed by the investigators by reviewing relevant literature in the field such as the Public Health Emergency Management Guidelines for Ethiopia (12), CDC's Knowledge, Skills, and Attitudes (KSAs) for the Public Health Preparedness and Response Core Competency Model (13) as well as the Hyogo Framework for Action 2005-2015 (14). Moreover, various training materials on public health emergency planning and management for districts through the Leadership Initiative for Public Health in East Africa (LIPHEA) Program were consulted and adapted to guide the study. The designed questionnaire was pretested by involving the data collectors as part of their practical training. The purpose of the pretest was to check the clarity and consistency of the questionnaire and to ensure if it was well understood by the data collectors. All the necessary revisions were made based on the pretest results before the commencement of the actual data collection process.

The questionnaire included socio-economic and demographic characteristics of respondents, their knowledge, experiences and training needs about disaster early warning, preparedness and response. The questions particularly focused on common disasters including drought, flood, epidemic diseases and fire and traffic accidents. The questionnaire was prepared in English and translated into local languages, Afaan Oromo and Amharic, and then back translated to English by a different translator to ensure consistency. A total of 10 data collectors and 4 supervisors, who had previous survey experience, were recruited and trained on the data collection tool and the procedure. Supervisors and investigators closely followed up the overall data collection process.
Data were checked immediately after collection for completeness and consistency, then coded and entered into SPSS computer software for windows version 20.0. After cleaning the data, descriptive statistics was computed and summary values such as frequency, percentage, mean and/or median were determined to describe the study findings and the results were presented using frequency tables and graphs. Bivariate analysis was employed to see the crude association between each exposure versus outcome variable. To control the effect of confounding factors or to get independently associated variables, each variable that was statistically significantly associated at $\mathrm{p}-$ value $<0.2$ in bivariate analysis was entered in to backward stepwise multiple logistic regression model. P-value $\leq 0.05$ was considered as statistically significant for all the independent variables in the final model. A few open ended questions were used to explore participants' knowledge about disaster and related concepts. Responses were thematized based on the available literature and then quantified for the purpose of describing the results, given the high response rate to the question. The proposal was ethically approved by Jimma University Ethical Review Board. Participation was voluntary and respondents were given a chance to refuse or discontinue the interview at any time. Confidentiality of the data was ensured and access to raw data was allowed only after a joint agreement by the research team members.

Early warning is defined as identification of a threat to disaster by closely and frequently monitoring and predicting the risk it poses. It provides timely and effective information to the public and to responders for effective response. Major indicators of early warning that are related to common disaster include occurrence of epidemic, malnutrition, increase in zoonotic disease; environmental changes such as air pollution and water quality changes. Disaster preparedness involves implementing a range of critical activities prior to the occurrence of emergency that are necessary to build, sustain and improve the operational capability to respond to and recover from disasters. On the other hand, disaster response focuses on rapid assessment and investigation of the incident, implementing control and prevention measures, and monitoring of the interventions (12). 
The CDC Knowledge, Skills and Attitudes (KSAs) for Public Health Preparedness and Response Core Competency Model (13) definitions of knowledge and attitudes were contextualized in measuring the respondents' knowledge and experiences concerning the concepts of disasters. Knowledge is defined as a process of remembering, relating or judging an idea about disasters. Therefore, it was captured as reported or rated by the participants, and thus it is a self-reported or self-rated knowledge. Similarly, training need was assessed by asking them about the generic skills required for managing common disasters. They had also ranked their needs for inservice short course trainings in terms of generic public health management skills: communication, disaster management, resource mobilization and health economics; risk analysis and field epidemiology. Therefore, it was the need that was actually felt by the participants.

\section{RESULTS}

Characteristics of the respondents: Overall, 377 health professionals took part in the study, making the response rate $93 \%$. Majority (63.4\%),

Table 1: Socio-demographic characteristics of the respondents in Jimma Zone, South West Ethiopia, March 2014

\begin{tabular}{|c|c|c|}
\hline Variables & Frequency & Percent \\
\hline \multicolumn{3}{|l|}{$\operatorname{Sex}(n=377)$} \\
\hline Male & 224 & 59.4 \\
\hline Female & 153 & 40.6 \\
\hline \multicolumn{3}{|l|}{ Age $(n=377)$} \\
\hline Less than 20 years & 4 & 1.1 \\
\hline $20-24$ years & 71 & 18.8 \\
\hline $25-34$ years & 205 & 54.4 \\
\hline $35-44$ years & 72 & 19.1 \\
\hline 45 years and above & 25 & 6.6 \\
\hline \multicolumn{3}{|l|}{ Marital status $(n=377)$} \\
\hline Single & 180 & 47.7 \\
\hline Married & 195 & 51.7 \\
\hline Divorced & 2 & 0.5 \\
\hline \multicolumn{3}{|c|}{ Highest level of education attained $(n=377)$} \\
\hline Certificate & 9 & 2.4 \\
\hline Diploma & 229 & 60.7 \\
\hline Bachelor's degree & 138 & 36.6 \\
\hline Master's degree & 1 & 0.3 \\
\hline \multicolumn{3}{|l|}{ Field of study/profession $(n=364)$} \\
\hline Nursing & 222 & 61.0 \\
\hline Medical laboratory & 38 & 10.4 \\
\hline Public health/health officer & 28 & 7.7 \\
\hline Pharmacy & 25 & 6.9 \\
\hline Midwifery & 17 & 4.7 \\
\hline Environmental health & 12 & 3.3 \\
\hline Medicine & 9 & 2.5 \\
\hline Others* & 13 & 3.6 \\
\hline \multicolumn{3}{|l|}{ Current job position $(n=377)$} \\
\hline Head of the organization & 6 & 1.6 \\
\hline Program coordinator & 42 & 11.1 \\
\hline Staff/expert & 329 & 87.3 \\
\hline \multicolumn{3}{|c|}{ Service year in the current organization $(n=377)$} \\
\hline$<1$ year & 97 & 25.7 \\
\hline $1-5$ years & 193 & 51.2 \\
\hline 6 years and above & 87 & 23.1 \\
\hline \multicolumn{3}{|l|}{ Total service year $(n=377)$} \\
\hline$<1$ year & 27 & 7.2 \\
\hline $1-5$ years & 194 & 51.5 \\
\hline $6-15$ years & 110 & 29.2 \\
\hline $16-25$ years & 33 & 8.8 \\
\hline 26 years and above & 13 & 3.4 \\
\hline
\end{tabular}

*Included Health Education and Behavioral Science, Health Extension Worker, Radiography, Integrated Emergency Obstetric Surgery and Anesthesia 
were from health centers, $59.4 \%$ were males and $54.4 \%$ were aged 25-34 years. Two hundred twenty nine $(60.7 \%)$, were educated at Diploma level. About two third $(61.0 \%)$ of the participants were nurse by profession and $51.2 \%$ had served in their current organization for 1-5 years (Table 1).

Common disasters: The participants were asked to rate the frequency of occurrence of common disasters in their locality in the past two years. Transport accidents, disease epidemics, infestations, environmental pollution, fire, drought and flood, in that order of importance, were mentioned as common disasters. Landslide and earthquake were reported to be less frequent (Table 2). Thirty three point five percent of the fire accidents $(n=167)$ were caused by electricity and the rest $(66.5 \%)$ by humans. One hundred forty $(37.1 \%)$ participants reported a total of 172 disease outbreaks in their localities in the past two years. Of these, $35.5 \%, 33.1 \%$ and $10.5 \%$ were malaria, measles and diarrhoeal disease epidemics, respectively.

Table 2: Occurrence of common disasters as reported by health professionals in Jimma Zone, South West Ethiopia, March 2014.

\begin{tabular}{lllll}
\hline \multirow{2}{*}{ Disaster category } & \multicolumn{4}{c}{ Frequency } \\
\cline { 2 - 5 } & Very frequent & Frequent & Less frequent & Not at all \\
\cline { 2 - 5 } & No. $(\%)$ & No. $(\%)$ & No. $(\%)$ & No. $(\%)$ \\
\hline Transport accidents $(\mathrm{\%}=375)$ & $62(16.5)$ & $124(33.1)$ & $129(34.4)$ & $60(16.0)$ \\
Disease epidemic(n=375) & $39(10.4)$ & $67(17.9)$ & $196(52.3)$ & $73(19.5)$ \\
Infestations(n=375) & $25(6.7)$ & $60(16.0)$ & $46(12.3)$ & $244(65.1)$ \\
Environmental pollution(n=377) & $23(6.1)$ & $34(9.0)$ & $82(21.8)$ & $238(63.1)$ \\
Fire(n=376) & $20(5.3)$ & $41(10.9)$ & $155(41.2)$ & $160(42.6)$ \\
Drought $(\mathrm{n}=370)$ & $11(3.0)$ & $27(7.3)$ & $71(19.2)$ & $261(70.5)$ \\
Flood(n=377) & $10(2.7)$ & $29(7.7)$ & $84(22.3)$ & $254(67.4)$ \\
Landslide(n=374) & $9(2.4)$ & $18(4.8)$ & $31(8.3)$ & $316(84.5)$ \\
Earthquake(n=377) & $8(2.1)$ & $11(2.9)$ & $44(11.7)$ & $314(83.3)$ \\
Explosion(n=371) & $3(0.8)$ & $10(2.7)$ & $58(15.6)$ & $300(80.9)$ \\
\hline
\end{tabular}

Knowledge about the concept of disaster: The participants were asked an open-ended question to describe their general knowledge about the concept of disaster. The great majority, (85.1\%), had tried to define the concept from various perspectives. However, 9.7\% of the respondents did not know about the concept at all and 5.2\% did not describe the concept comprehensively, or misconceived it in some way. Some described the concept by listing the common types of disasters. They defined disaster as the occurrence of a natural or manmade emergency accident or hazard like fire, car accident, disease outbreak, flood, earthquake or drought that affects human beings and their environments. Some viewed the concept from the emergency nature of the response it requires. According to them, it needs readiness of different institutions at any time as disaster is beyond the control of human beings. There were also respondents who misconceived the concept. For instance, a few participants defined disaster as follows: "Disaster means when damage occurs accidentally to the natural resources by an unknown cause." "Disaster is any accident that comes from God which destroys human life."

"Since we are being protected by the supernatural power, we have never seen the impact of any disaster."

Sixty eight percent of the health professionals properly described the abbreviation "ABC" in the first aid management of a trauma victim as Airway Breathing Circulation. Nevertheless, $23.1 \%$ did not know while it and the rest knew it partially. The majority, $67.9 \%$, reported opening airway as the first step of cardiopulmonary resuscitation during emergency situations followed by supplying oxygen $(17.5 \%)$, artificial respiration (13.3\%), closed cardiac massage (3.4\%) and cerebral resuscitation (1.6\%). Participants also rated their knowledge about early warning information, preparedness and response regarding the common disasters. The majority felt that they had poor knowledge on early warning indicators of drought (48.0\%) and flood (48.0\%); on 
preparedness to drought $(50.8 \%)$ and flood (47.7\%); on responding to drought $(51.1 \%)$ and flood $(42.6 \%)$. On composite scale, they generally perceived to have adequate $(29.4 \%)$, moderate
$(32.4 \%)$ and poor $(38.2 \%)$ knowledge about early warning information, preparedness and response to common disasters (Table 3 ).

Table 3: Health professionals' knowledge about early warning information, preparedness and response regarding the common disasters, Jimma Zone, South West Ethiopia, March 2014.

\begin{tabular}{llll}
\hline Your knowledge regarding the following areas is: & \multicolumn{3}{c}{ Ratings } \\
\cline { 2 - 4 } & Adequate & Moderate & Poor \\
\cline { 2 - 4 } & o. $(\%)$ & №. $(\%)$ & №. $(\%)$ \\
\hline Early warning indicators of a flood disaster & $73(19.4)$ & $123(32.6)$ & $181(48.0)$ \\
Preparedness for a flood disaster & $54(14.3)$ & $136(36.1)$ & $187(49.6)$ \\
Response to a flood disaster & $54(14.3)$ & $160(42.4)$ & $163(43.2)$ \\
Preparedness for disaster due to traffic accident & $42(11.1)$ & $213(56.5)$ & $122(32.4)$ \\
Response to disaster due to traffic accident & $82(21.8)$ & $205(54.4)$ & $90(23.9)$ \\
Preparedness for a fire disaster & $72(19.1)$ & $193(51.2)$ & $112(29.7)$ \\
Response to a fire disaster & $80(21.2)$ & $192(50.9)$ & $105(27.9)$ \\
Early warning indicators of occurrence of drought & $62(16.4)$ & $136(36.1)$ & $179(47.5)$ \\
Preparedness for a disaster due to drought & $46(12.2)$ & $141(37.4)$ & $190(50.4)$ \\
Response to a disaster due to drought & $58(15.4)$ & $128(34.0)$ & $191(50.7)$ \\
Early warning indicators of an outbreak & $98(26.0)$ & $171(45.4)$ & $108(28.6)$ \\
Preparedness for an outbreak & $111(29.4)$ & $176(46.7)$ & $90(23.9)$ \\
Response to an outbreak & $119(31.6)$ & $179(47.5)$ & $79(21.0)$ \\
Composite knowledge & $111(29.4)$ & $122(32.4)$ & $144(38.2)$ \\
\hline
\end{tabular}

Possible public health consequences of disaster: The participants were also asked open-ended questions to describe the possible public health consequences of a disaster on humans, environment and infrastructures. The majority, $(84.3 \%)$, reported that disaster has direct adverse health related effects on human beings. Specifically, most of them said that it causes physical disability as a result of injury expressed as fracture, amputation and ultimately, death. They also said that it increases vulnerability to various contagious diseases and food insecurity or drought. Psychological stress, mental illnesses like depression and sense of loneliness were also emphasized.

One hundred fourteen (30.2\%) viewed the public health consequences of a disaster on humans primarily from socioeconomic perspectives. They said that disaster can destruct property leading directly to loss of economy, homelessness and joblessness which further lead to poverty making the affected community rely on external support. They also mentioned that disaster can lead to social problems like increasing number of dependants such as orphans, lack of peace and security, migration and displacement.

Regarding the possible consequences of disasters on environment, $65.8 \%$ of the participants reported environmental pollution, especially of soil, water and air, as major consequence which would potentially affect life on earth. Some related the consequence to climate change or ecosystem disturbance, especially, global warming, which favors disasters like disease outbreak, flooding, and drought. Seventy nine $(21 \%)$ respondents associated the environmental consequences with destruction of land and other natural resources such as deforestation and soil erosion, creating inconvenience for farming and other development activities. According to $91.5 \%$ of the respondents, destruction of power plants, roads and other communication infrastructures due to disaster affects quality and quantity of public health services production and delivery since it affects resources of both health and other development sectors which are vital for ensuring public health. Infrastructural damages lead to limited operation 
of routine activities, increased work load plus wastage of supplies and materials.

Disaster preparedness: Community rescue training and knowledge propagation, material reserve and population vulnerability assessment were mentioned as important disaster preparedness strategies by $71.1 \%, 57.3 \%$ and $41.9 \%$ of the respondents, respectively. Awareness creation or educating the community about environmental protection, disease transmission, early preparedness and ways of taking immediate action at the time of disaster were the specific aspects suggested by the participants. They also stressed the need for early preparation by the government for instance, planned resettlement, strengthening routine disease control campaigns, training health professionals on disaster response and rehabilitation plan once disaster occurs. The majority $(70.3 \%)$ reported shouting for help as an appropriate action for a person in a fire accident; $30.5 \%$ opted for covering mouth and nose with wet towels and crawl along the wall to safety exit; and $30.2 \%$ would struggle to put out the fire. Other actions included, prohibiting people to use oil on the body, transporting the victim to the nearest health facility by calling ambulance, undressing the victim, praying to God, rolling the victim on the ground, and using water and soil to put off the fire.

The participants also rated their level of agreement on pre-hospital or pre-health facility and hospital or health facility based fire management actions on Likert scaled items. The vast majority agreed with all of the items given under pre-hospital or pre-health facility fire management actions. The lowest agrrement rate was $71.9 \%$ for searching, rescuing and evacuation; and the highest was $88.1 \%$ for initial triaging and providing first aid. Among the items for hospital or health facility fire management actions, assessing magnitude, severity and number of victims was rated the lowest (70.8\%); monitoring, evaluation and rehabilitation were the highest (90.7\%) (Table 4).

Training Need: Seventy two (20.6\%) of the health professionals had ever been trained on any topic regarding disaster during two years prior to the study. One third $(30.6 \%)$ of them, $(n=72)$ were trained on disease epidemic and drought each, followed by, fire and traffic accidents (13.9\% each), and flood (11.1\%).Three hundred fifty (92.8\%) participants needed additional training regarding disaster preparedness and response. The majority $(71.4 \%)$ were most interested in the national and local disaster reduction and preparedness plans followed by basic principles of disaster assistance $(70.6 \%)$, treatment principles and first-aid skills (58.9\%), post-disaster psychological relief $(46.9 \%)$, post-disaster epidemic prevention (32.3\%), on-site triage $(30.9 \%)$ and the rescue and transport of the wounded (30.6\%). The preferred training modalities were face to face short term $(79.5 \%)$, on-job or onsite $(12.4 \%)$, face to face long term $(4.6 \%)$ and online or distance modality (3.5\%). Finally, the participants ranked their felt needs for in-service short course trainings. The following topics were rated as very important: communication skills $(76.9 \%)$, disaster management $(67.6 \%)$, resource mobilization and health economics $(58.9 \%)$, risk analysis $(56.8 \%)$ and field epidemiology and ecosystem health $(54.6 \%)$ (Table 5). 
Table 4: Health professionals' level of agreement on pre hospital or pre health facility and hospital or health facility based fire management actions, Jimma Zone, South West Ethiopia, March 2014

\begin{tabular}{|c|c|c|c|c|}
\hline \multirow{3}{*}{ Items } & \multicolumn{4}{|c|}{ Level of agreement } \\
\hline & Don't know & Disagree & Uncertain & Agree \\
\hline & No. $(\%)$ & №. $(\%)$ & №. $(\%)$ & №. $(\%)$ \\
\hline \multicolumn{5}{|l|}{ Pre hospital or health facility fire management includes: } \\
\hline Organize and establish control authority $(\mathrm{n}=377)$ & $28(7.4)$ & $22(5.8)$ & $41(10.9)$ & 286(75.9) \\
\hline Extinguish the fire & $16(4.2)$ & 21(5.6) & $46(12.2)$ & 294(78.0) \\
\hline Conduct Rapid Needs Assessment $(\mathrm{n}=375)$ & $19(5.0)$ & 20(5.3) & $51(13.5)$ & $285(75.6)$ \\
\hline Search and Rescue and evacuation of victims $(n=376)$ & $20(5.3)$ & $23(6.1)$ & $62(16.4)$ & 271(71.9) \\
\hline Initial triage and First Aid to the victims $(n=377)$ & $5(1.3)$ & $6(1.6)$ & $34(9.0)$ & $332(88.1)$ \\
\hline Transport victims to health facility $(\mathrm{n}=375)$ & $6(1.6)$ & $10(2.7)$ & $31(8.2)$ & $328(87.0)$ \\
\hline Use available resources \& mobilize for others if needed $(n=370)$ & $4(1.1)$ & $14(3.7)$ & $39(10.3)$ & $313(83.0)$ \\
\hline \multicolumn{5}{|l|}{ Hospital or health facility based operations of fire management include: } \\
\hline Activate hospital or health facility contingency plans $(n=376)$ & 21(5.6) & $18(4.8)$ & $52(13.8)$ & $285(75.6)$ \\
\hline Assess magnitude, severity, number of victims $(n=377)$ & $11(2.9)$ & $32(8.5)$ & $67(17.8)$ & $267(70.8)$ \\
\hline Establish advance teams to the fire site $(n=375)$ & $13(3.4)$ & $17(4.5)$ & $41(10.9)$ & $304(80.6)$ \\
\hline Establish receiving mechanism and prepare admission ward $(\mathrm{n}=371)$ & $11(2.9)$ & $11(2.9)$ & $26(6.9)$ & $323(85.7)$ \\
\hline Identification of burn emergency team $(n=374)$ & $11(2.9)$ & $15(4.0)$ & $47(12.5)$ & $301(79.8)$ \\
\hline Treat and manage victims according to degree of burns $(n=374)$ & 0 & $11(2.9)$ & $26(6.9)$ & $337(89.4)$ \\
\hline Refer the patient to higher health institutions $(n=374)$ & $2(.5)$ & $15(4.0)$ & $37(9.8)$ & $320(84.9)$ \\
\hline Establish special burn treatment centres $(n=375)$ & $12(3.2)$ & $39(10.3)$ & $52(13.8)$ & $272(72.1)$ \\
\hline Alleviate shock by fluids, transfusion, surgery etc $(n=374)$ & $9(2.4)$ & $16(4.2)$ & $34(9.0)$ & $315(83.6)$ \\
\hline Certify death if any and provide mortuary facilities $(n=370)$ & $15(4.0)$ & $17(4.5)$ & $38(10.1)$ & $300(79.6)$ \\
\hline Keep records and inform appropriate authorities $(\mathrm{n}=375)$ & $20(5.3)$ & $6(1.6)$ & $22(5.8)$ & $327(86.7)$ \\
\hline Monitoring, evaluation and rehabilitation $(n=374)$ & $2(.5)$ & $8(2.1)$ & $22(5.8)$ & $342(90.7)$ \\
\hline
\end{tabular}


Table 5: Health professionals' needs for in-service short course training in Jimma Zone, South West Ethiopia, March 2014.

\begin{tabular}{|c|c|c|c|c|}
\hline \multirow[t]{2}{*}{ Areas of Training Needed } & $\begin{array}{l}\text { Not } \\
\text { important }\end{array}$ & $\begin{array}{l}\text { Little } \\
\text { importance }\end{array}$ & Important & $\begin{array}{l}\text { Very } \\
\text { important }\end{array}$ \\
\hline & №. $(\%)$ & No. $(\%)$ & No..$(\%)$ & №. $(\%)$ \\
\hline Communication skills $(\mathrm{n}=377)$ & $4(1.1)$ & $20(5.3)$ & $63(16.7)$ & $290(76.9)$ \\
\hline Disaster management $(n=377)$ & $11(2.9)$ & 21(5.6) & $90(23.9)$ & $255(67.6)$ \\
\hline Resource mobilization \& health economics $(n=377)$ & $6(1.6)$ & $22(5.8)$ & $127(33.7)$ & $222(58.9)$ \\
\hline Risk analysis $(\mathrm{n}=375)$ & $14(3.7)$ & $25(6.6)$ & $122(32.4)$ & $214(56.8)$ \\
\hline Field epidemiology \& ecosystem health $(n=374)$ & $1(.3)$ & $44(11.7)$ & $123(32.6)$ & $206(54.6)$ \\
\hline Leadership skills $(\mathrm{n}=377)$ & $19(5.0)$ & $47(12.5)$ & $123(32.6)$ & $188(49.9)$ \\
\hline
\end{tabular}

Factors associated with health professionals' self-rated knowledge about early warning information, preparedness and response regarding common disasters: Binary logistic regression analysis was done to examine factors associated with perceived poor knowledge among the health professionals about early warning information, preparedness and response regarding the common disasters. The three scaled composite knowledge score of the health professionals shown in Table 5 was dichotomized to be used as a dependent variable by merging those who rated their knowledge as 'medium' and 'adequate' as "good perceived knowledge" while maintaining those who rated to be "poor" as "poor perceived knowledge". Overall, those who had good perceived knowledge were $233(61.8 \%)$, whereas those who had poor perceived knowledge were 144(38.2\%).

The relationships between certain sociodemographic characteristics of the respondents such as sex, age, marital status and highest level of education attained and and history of training on disaster were assessed was examined. Job related characteristics such as type of institution from which the participants were represented, current job position, field of study or profession, service year in current organization, and total service year were also assessed. Initially, the relationships between each explanatory variable and the dependent variable were investigated independently, and then, all were entered at once to control or adjust for potential confounding effects. Except for field of study/profession and service year in current organization, which were initially (unadjusted), associated with health professionals poor perceived knowledge about early warning information, preparedness and response regarding the common disasters, all explanatory variables were shown to have no association with the health professionals' poor perceived knowledge (Table 6).

\section{DISCUSSION}

Despite the fact that malaria, measles and diarrhoeal diseases are at the top of the Ethiopian Ministry of Health's agenda for priority interventions (15), they were shown to be top ranking causes of epidemics in the study area. This contradicts with the generally decreasing trend of malaria epidemic at national level since recent years. It also contradicts with the fact that essential health service packages against the above epidemics, that is, i.e, prevention and control of malaria, hygiene and sanitation, expanded program on immunization and integrated disease surveillance and response are among the components of the country's flagship program, the health service extension program (15). The concept of disaster was not comprehensively described by majority $(85.1 \%)$ of the health professionals in the study area. This finding is lower than a study conducted in South Africa (11), which reported that $92 \%$ of the study participants knew what disaster and disaster plan are. In addition, misconceptions about the concept among the health professionals were evidenced in this study, some participants believing that disaster is caused by a super natural power, God. This implies a considerable gap regarding the concept of disaster, the study participants being health professionals. Similarly, $23.1 \%$ did not know the acronym 'ABC' in the 
Table 6: Factors associated with perceived health professionals' knowledge about early warning information, preparedness and response regarding the common disasters, Jimma Zone, South West Ethiopia, March 2014.

\begin{tabular}{|c|c|c|c|c|c|c|c|}
\hline \multirow[t]{2}{*}{ Variables } & \multicolumn{3}{|c|}{ Comprehensive knowledge about common disasters } & \multirow[t]{2}{*}{ COR } & \multirow{2}{*}{ 95\% CI for COR } & \multirow[t]{2}{*}{ AOR } & \multirow{2}{*}{$95 \% \mathrm{CI}$ for $\mathrm{AOR}$} \\
\hline & $\begin{array}{l}\text { Poor perceived knowledge } \\
(n=144)\end{array}$ & $\begin{array}{l}\text { Good perceived knowledge } \\
(\mathrm{n}=233)\end{array}$ & $\begin{array}{l}\text { Total } \\
(\mathrm{n}=377)\end{array}$ & & & & \\
\hline \multicolumn{8}{|l|}{ Institution } \\
\hline Hospital & $40(27.8 \%)$ & $66(28.3 \%)$ & $106(28.1 \%)$ & 0.86 & $0.37,1.98$ & 1.04 & $0.28,3.83$ \\
\hline Health center & $93(64.6 \%)$ & $146(62.7 \%)$ & $239(63.4 \%)$ & 0.82 & $0.37,1.78$ & 1.02 & $0.29,3.47$ \\
\hline Health office & $11(7.6 \%)$ & $21(9.0 \%)$ & $32(8.5 \%)$ & 1 & - & 1 & - \\
\hline \multicolumn{8}{|l|}{ Henta } \\
\hline Male & $93(64.6 \%)$ & $131(56.2 \%)$ & $224(59.4 \%)$ & 1.42 & $0.93,2.18$ & 1.27 & $0.79,2.03$ \\
\hline Female & $51(35.4 \%)$ & $102(43.8 \%)$ & $153(40.6 \%)$ & 1 & - & & \\
\hline \multicolumn{8}{|l|}{ Age in years } \\
\hline$<20$ & $4(2.8 \%)$ & $0(0 \%)$ & $4(1.1 \%)$ & - & - & - & - \\
\hline 20-24 & $34(23.6 \%)$ & $37(15.9 \%)$ & $71(18.8 \%)$ & 0.72 & $0.29,1.83$ & 0.29 & $0.07,1.16$ \\
\hline $25-34$ & $81(56.2 \%)$ & $124(53.2 \%)$ & $205(54.4 \%)$ & 1.02 & $0.44,2.38$ & 0.57 & $0.17,1.9$ \\
\hline $35-44$ & $15(10.4 \%)$ & $57(24.5 \%)$ & $72(19.1 \%)$ & 2.53 & $0.95,6.76$ & 1.52 & $0.45,5.07$ \\
\hline$>=45$ & $10(6.9 \%)$ & $15(6.4 \%)$ & $25(6.6 \%)$ & 1 & 0 & 1 & 0 \\
\hline \multicolumn{8}{|l|}{ Marital status } \\
\hline Single & $73(50.7 \%)$ & $107(45.9 \%)$ & $180(47.7 \%)$ & 1 & - & 1 & - \\
\hline Married & $69(47.9 \%)$ & $126(54.1 \%)$ & $195(51.7 \%)$ & 1.25 & $0.82,1.89$ & 0.83 & $0.48,1.43$ \\
\hline \multicolumn{8}{|l|}{ Current job } \\
\hline Head & $2(1.4 \%)$ & $4(1.7 \%)$ & $6(1.6 \%)$ & 1.24 & $0.22,6.87$ & 1.91 & $0.29,12.3$ \\
\hline Program coordinator & $16(11.1 \%)$ & $26(11.2 \%)$ & $42(11.1 \%)$ & 1.01 & $0.52,1.95$ & 1.35 & $0.51,3.59$ \\
\hline Staff/expert & $126(87.5 \%)$ & $203(87.1 \%)$ & $329(87.3 \%)$ & 1 & - & 1 & - \\
\hline \multicolumn{8}{|l|}{ Level of education } \\
\hline Certificate & $2(1.4 \%)$ & $7(3.0 \%)$ & $9(2.4 \%)$ & 1 & - & - & - \\
\hline Diploma & $74(51.4 \%)$ & $155(66.5 \%)$ & $229(60.7 \%)$ & 0.59 & $0.12,2.95$ & 0.7 & $0.11,4.38$ \\
\hline Bachelor's degree & $67(46.5 \%)$ & $71(30.5 \%)$ & $138(36.6 \%)$ & 0.3 & $0.06,1.51$ & 0.45 & $0.07,2.97$ \\
\hline \multicolumn{8}{|l|}{ Profession } \\
\hline Nursing & $71(50.4 \%)$ & $151(67.7 \%)$ & $222(61.0 \%)$ & 1 & - & 1 & - \\
\hline $\mathrm{HO}$ & $14(9.9 \%)$ & $14(6.3 \%)$ & $28(7.7 \%)$ & 0.47 & $0.21,1.04$ & 2.65 & $0.68,10.29$ \\
\hline MD & $2(1.4 \%)$ & $7(3.1 \%)$ & $9(2.5 \%)$ & 1.65 & $0.33,8.12$ & 1.96 & $0.4,9.56$ \\
\hline Environmental Health & $8(5.7 \%)$ & $4(1.8 \%)$ & $12(3.3 \%)$ & 0.24 & $0.07,0.81$ & 5.41 & $0.63,46.1$ \\
\hline Pharmacy & $14(9.9 \%)$ & $11(4.9 \%)$ & $25(6.9 \%)$ & 0.37 & $0.16,0.86$ & 1.15 & $0.16,8.1$ \\
\hline $\mathrm{Lab}$ & $19(13.5 \%)$ & $19(8.5 \%)$ & $38(10.4 \%)$ & 0.47 & $0.24,0.94$ & 1.03 & $0.21,5.10$ \\
\hline Midwifery & $5(3.5 \%)$ & $12(5.4 \%)$ & $17(4.7 \%)$ & 1.13 & $0.38,3.33$ & 1.68 & $0.37,7.61$ \\
\hline Others* & $8(5.7 \%)$ & $5(2.2 \%)$ & $13(3.6 \%)$ & 0.29 & $0.09,0.93$ & 3.69 & $0.64,21.2$ \\
\hline \multicolumn{8}{|l|}{ Service year in current job } \\
\hline Less than 1 year & $48(33.3 \%)$ & $49(21.0 \%)$ & $97(25.7 \%)$ & 1 & - & 1 & - \\
\hline $1-5$ years & $72(50.0 \%)$ & $121(51.9 \%)$ & $193(51.2 \%)$ & 1.65 & $1.01,2.69$ & 0.45 & $0.17,1.19$ \\
\hline 6 years and above & $24(16.7 \%)$ & $63(27.0 \%)$ & $87(23.1 \%)$ & 2.57 & $1.39,4.76$ & 0.92 & $0.39,2.17$ \\
\hline \multicolumn{8}{|l|}{ Total service year } \\
\hline 5 years or less & $94(65.3 \%)$ & $127(54.5 \%)$ & $221(58.6 \%)$ & 1 & - & 1 & - \\
\hline More than 5 years & $50(34.7 \%)$ & $106(45.5 \%)$ & $156(41.4 \%)$ & 0.64 & $0.27,1.53$ & 0.31 & $1.0,67.8$ \\
\hline \multicolumn{8}{|l|}{ Ever trained on disaster } \\
\hline Yes & $25(17.9 \%)$ & $47(20.9 \%)$ & $72(19.7 \%)$ & 1 & - & 1 & - \\
\hline No & $115(82.1 \%)$ & $178(79.1 \%)$ & $293(80.3 \%)$ & 0.82 & $0.48,1.41$ & 0.84 & $0.44,1.61$ \\
\hline
\end{tabular}


management of a trauma victim, which is far below the South African study (11). Overall, $29.4 \%, 32.4 \%$ and $38.2 \%$ of the participants rated their knowledge about early warning information, preparedness and response regarding the common disasters as adequate, medium and poor. A study in Shanghai depicted that $5.7 \%, 62.9 \%$ and $31.4 \%$ of the health workers' self-estimation of disaster medicine knowledge was well, moderate and little, respectively (16). Another study conducted in Georgia among public health professionals similarly identified gaps in the selfreported current competency levels on emergency preparedness (17). The present finding, therefore, has revealed a questionable competency of the health professionals in the study area as it relates to disaster plan and response.

Generally, the health professionals had comprehensive views about the public health consequences of disaster on human, environment and infrastructure. This might partly reflect their understanding of the complexity of disaster, intersectoral nature of healthcare and the dynamics between the determinants of good health, which can be considered as an opportunity that should be strengthened further. This study also revealed that only $20.6 \%$ of the health professionals had ever been trained despite the vast majority (92.8\%) needed additional training on disaster preparedness and response. This is lower than that of the South African study (18), where $52 \%$ of the health workers reported that there was ongoing training at their hospitals On the other hand, the present finding shows better status than the study in Shanghai (16), which revealed that only $1.3 \%$ had received systematic disaster medicine training. This study indicates that a large majority of the health professionals had no opportunities to update themselves on the latest and broader perspective of disaster prevention and disaster management, calling for well-organized programs where refresher trainings are conducted at a desirable interval. Finally, this study has some limitations.

Recall bias might have been introduced as the respondents were asked about events that occurred in the past. Accuracy of self-reported responses was validated objectively. In addition, although private practitioners are important stakeholders during major disaster situations, they were excluded from the study, which may have implication in involving them in possible future trainings or interventions.

In conclusion, malaria, measles and diarrhoeal diseases accounted for the majority of the recent outbreaks. Although the majority had good knowledge about the public health consequences of disaster in general, a considerable number of health professionals had limited knowledge about the concept of disaster and response to certain specific disasters. About a quarter could not be able to describe the acronym "ABC" in first aid management of trauma. About a third had inadequate knowledge about early warning information, preparedness and response regarding common disasters. In addition, they had limited opportunities for training on topics related to disaster, despite their felt needs.

Therefore, it is recommended that the health sector needs to check its implementation of the nationally adopted intervention strategies against malaria, measles and diarrhoeal diseases. Training should be provided for health professionals focusing on the specific gaps identified. We also recommend that those who are interested in the field conduct similar studies involving sectors other than health in order to have comprehensive understanding of the situation in the zone with regard to various disasters.

\section{ACKNOWLEDGEMENTS}

The realization of this research project was made possible by the generous support of the Global Disaster Preparedness Center and Response 2 Resilience. We are therefore grateful to the Center.We appreciate the collaborative support we got from he Red Cross Society of Ethiopia, Jimma Zone Branch Office, throughout the project's life. We are also grateful to Jimma Zone Health Office and Health Offices of the districts included in the study for their facilitatation especially the field work. Our gratitude should also go to the data collectors. Last, but not least, we acknowledge the contribution of Jimma University. 


\section{REFERENCES}

1. ADPC. Community Based Disaster Risk Management; A Framework for Reducing Risk: Part one.

2. Su T, Han X, Chen F, Du Y, Zhang H, et al. Knowledge Levels and Training Needs of Disaster Medicine among Health Professionals, Medical students and Local Residents in Shanghai, China. PLoSONE, 2013; 8(6): e67041. doi:10.1371/journal.pone.0067041

3. International Federation of Red Cross and Red Crescent Societies Ethiopia: How Law and Regulation Supports DRR, Country Case Study Report, April 2013.

4. Zhang Z, Wang W, Shi Z, Wang L, Zhang J. Mental health problems among the survivors in the hard-hit areas of the Yushu earth quake. PLoSOne, 2012;7(10): e46449.

5. Pietrzak RH, Tracy M, Galea S, Kilpatrick $\mathrm{DG}$, Ruggiero KJ, et al. Resilience in the face of disaster: Prevalence and longitudinal course of mental disorders following hurricane Ike. PLoSOne, 2012;7(6): e38964.

6. Anda K, Praneed S, Wipa SS. Knowledge and skills of Emergency Care During Disaster For Community Health Volunteers: A Literature Review. Nurse Media Journal of Nursing: 2012;2 (2): 371-381

7. You C,ChenX,Yao L: How China responded to the May 2008 Earthquake during the emergency and rescue period. $J$ Public Health Policy, 2009;30:379-393.

8. David M, Charles D Irwin R. Preparing Health Professions Students for Terrorism, Disaster, and Public Health Emergencies: Core Competencies. Academic Medicine, 2005;80(6): 517-526.

9. Scott LA, Carson DS, Greenwell IB: Disaster101: an overall approach to disaster medicine training for health professionals. $J$ Emerg Med; 2010;39:220-226.

10. Kaiser HE, Barnett DJ, HsuEB, Kirsch TD, James JJ, et al: Perspectives of future physicians on disaster medicine and public health preparedness: challenges of building a capable and sustainable auxiliary medical workforce. Disaster Med Public Health Prep, 2009; 3:210-216.

11. Rosemary MM. Knowledge, Attitudes and Practices of Health Care Workers Regarding Disaster Preparedness at Johannesburg Hospital in Gauteng Province (Masters Thesis), South Africa, 2008.

12. Ethiopian Health and Nutrition Research Institute (EHNRI). Public Health Emergency Management: Guidelines for Ethiopia; 2012, Addis Ababa.

13. Centers for Disease Control and Prevention (CDC), Office of Public Health Preparedness and Response; and Association of Schools of Public Health: Knowledge, Skills, and Attitudes (KSAs) for the Public Health Preparedness and Response Core Competency Model; 2012, Public Health Preparedness \& Response.

14. United Nations: International Strategy for Disaster Reduction, Hyogo Framework for Action 2005-2015: Building the Resilience of Nations and Communities to Disasters; 2005, Extract from the final report of theWorld Conference on Disaster Reduction(A/CONF.206/6).

15. Federal Ministry of Health. Health Extension Program in Ethiopia. 2007. Addis Ababa, Ethiopia

16. Tadesse L, Ardalan A. Health Sector Initiatives for Disaster Risk Management in Ethiopia: A Narrative Review. PLOS Current Disasters, 2014; Doi:10.1371/currents.dis.949664319ad45131 3b499f9c90cd9c0f.

17. Thomas M, Amy S. Training Needs Assessment by Berrien County Health Department: Project Public Health Ready. Draft, 2006.

18. Wendy Childers, Melissa Alperin, and Kathleen R. Miner. Emergency Preparedness in Georgia: An Assessment of Public Health Training Needs, American Journal of Health Education, 2005; 36 (5): 287-294. 